\title{
Applications of Natural Fibers and Its Composites: An Overview
}

\author{
M. R. Sanjay ${ }^{1}$, G. R. Arpitha', L. Laxmana Naik ${ }^{1,2}$, K. Gopalakrishna², B. Yogesha ${ }^{1}$ \\ ${ }^{1}$ Department of Mechanical Engineering, Malnad College of Engineering, Visvesvaraya Technological University, \\ Belagavi, India \\ 2Jain University, Bangalore, India \\ Email: sanjaymrgech@gmail.com
}

Received 8 February 2016; accepted 8 March 2016; published 11 March 2016

Copyright (C) 2016 by authors and Scientific Research Publishing Inc.

This work is licensed under the Creative Commons Attribution International License (CC BY).

http://creativecommons.org/licenses/by/4.0/

(c) (i) Open Access

\begin{abstract}
In the present scenario, there has been a rapid attention in research and development in the natural fiber composite field due to its better formability, abundant, renewable, cost-effective and eco-friendly features. This paper exhibits an outline on natural fibers and its composites utilized as a part of different commercial and engineering applications. In this review, many articles were related to applications of natural fiber reinforced polymer composites. It helps to provide details about the potential use of natural fibers and its composite materials, mechanical and physical properties and some of their applications in engineering sectors.
\end{abstract}

\section{Keywords}

\section{Natural Fiber, Natural Fiber Composites, Polymers, Applications}

\section{Introduction}

Natural fiber is a type of renewable sources and a new generation of reinforcements and supplements for polymer based materials. The development of natural fiber composite materials or environmentally friendly composites has been a hot topic recently due to the increasing environmental awareness. Natural fibers are one such proficient material which replaces the synthetic materials and its related products for the less weight and energy conservation applications. The application of natural fiber reinforced polymer composites and natural-based resins for replacing existing synthetic polymer or glass fiber reinforced materials in huge. Automotive and aircrafts industries have been actively developing different kinds of natural fibers, mainly on hemp, flax and sisal and bioresins systems for their interior components. High specific properties with lower prices of natural fiber composites are making it attractive for various applications [1] [2]. 
The applications of natural fibers are growing in many sectors such as automobiles, furniture, packing and construction. This is mainly due to their advantages compared to synthetic fibers, i.e. low cost, low weight, less damage to processing equipment, improved surface finish of moulded parts composite, good relative mechanical properties, abundant and renewable resources [3]. Natural fibers are used in various applications such as building materials, particle boards, insulation boards, human food and animal feed, cosmetics, medicine and for other biopolymers and fine chemicals [4]. Table 1 shows the comparison between natural and synthetic fibers. Table 1 represents the natural fibers that have moderate mechanical properties when compared to synthetic fibers like glass, carbon, kevlar etc., but the major disadvantage of natural fibers is high moisture sensitivity.

\section{Overview and Applications of Natural Fibers}

Among all the natural fiber-reinforcing materials, areca appears to be a promising material because it is inexpensive, availability is abundant and a very high potential perennial crop. It belongs to the species Areca catechu L., under the family palmecea and originated in the Malaya peninsular, East India. Major industrial cultivation is in East India and other countries in Asia. In India, areca nut cultivation is coming up on a large scale basis with a view to attaining self sufficiency in medicine, paint, chocolate, Gutka, etc. It is estimated that about 6 Lakh tonnes of areca husk is available in south West-India. The husk of the Areca is a hard fibrous portion covering the endosperm. It constitutes $30 \%-45 \%$ of the total volume of the fruit. Areca husk fibers are predominantly composed of hemicelluloses and not of cellulose. In Table 1 the chemical composition of Areca fibers is shown along with few known fibers. Areca fibers contain 13\% to $24.6 \%$ of lignin, 35\% to $64.8 \%$ of hemicelluloses, $4.4 \%$ of ash content and remaining $8 \%$ to $25 \%$ of water content [6]. It is a well known fact that banana is one of the oldest cultivated plants in the world. The word "banana" comes from the Arabic language and means 'finger'. It belongs to the Musaceae family and there are approximately 300 species, but only 20 varieties are used for consumption. Approximately 70 million metric tons of bananas are produced every year by the tropical and subtropical regions of the world. The nutritional facts of banana (100 g pulp) are as follows: carbohydrates18.8 g; protein-1.15 g; fat-0.18 g; water-73.9 g; vitamins C1 B1 B2 B6 E, other minerals- 0.83 g and 81 $\mathrm{kcal}$. Banana plants generally produce 30 large leaves (almost $2 \mathrm{~m}$ long and 30 - $60 \mathrm{~cm}$ wide) [7]. Bamboo belongs to the grass family Bambusoideae, which consists of cellulose fiber embedded in a lignin matrix. Bamboo has several advantages over other plant fibers such as its low density, low cost, high mechanical strength, stiffness, high growth rate and its ability to fix atmospheric carbon dioxide. Bamboo also has some disadvantages for various applications, including high moisture content, the difficulty of extracting fine and straight fibers, and thermal degradation during manufacturing. More than 1000 species of bamboo and approximately 70 genera grow naturally in diverse climates, with particular abundance in Asia and South America. Bamboo has traditionally been used in construction and as a material for the manufacture of tools for daily living due to its high strength to weight ratio [8]. Hemp is naturally one of the most ecologically friendly fibers and also the oldest. Cannabis Sativa L. is the scientific name for the hemp plant. The Columbia History of the World states that the oldest relics of human industry are bits of hemp fabric discovered in tombs dating back to approximately 8000 BC. Hemp is an annual plant native to central Asia and known to have been grown for more than 12,000 years. It probably reached central Europe in the Iron Age and there is evidence of its growth in the UK by the Anglo Saxons (800 - 1000 AD). It is now grown mostly in the EU, Central Asia, Philippines, and China. According to Food and Agriculture Organisation (FAO), almost half of the world's industrial hemp supply is grown in China, with most of the remainder being cultivated in Chile, France, the Democratic People's Republic of Korea, and Spain [9].

Table 1. Comparison between natural fibers and synthetic fibers [5].

\begin{tabular}{|c|c|c|c|}
\hline Aspects & Property & Natural fibers & Synthetic fibers \\
\hline \multirow{3}{*}{ Technical } & Mechanical properties & Moderate & High \\
\hline & Moisture sensitivity & High & Low \\
\hline & Thermal sensitivity & High & Low \\
\hline \multirow{3}{*}{ Environmental } & Resource & Infinite & Limited \\
\hline & Production & Low & High \\
\hline & Recyclability & Good & Moderate \\
\hline
\end{tabular}


Jute is a bast fiber whose scientific name is Corchorus capsularis of Tiliaceae family. Plant of jute takes nearly 3 months to grow to a height of 12 - 15 feet. Jute plant is cut and kept immersed in the water for Retting process during season. The inner stem and outer gets separated and the outer plant gets individualized to form fibers. Jute fiber is known as golden fiber of Bangladesh, jute is an important fiber of Eastern Indian and Bangladesh [10]. Kenaf is one of the natural (plant) fibers used as reinforcement in Polymer Matrix Composites (PMCs). Kenaf (Hibiscus cannabinus L. family Malvacea) has been found to be an important source of fiber for composites, and other industrial applications. Kenaf is well known as a cellulosic source with both economic and ecological advantages; in 3 month (after sowing the seeds), it is able to grow under a wide range of weather conditions, to a height of more than $3 \mathrm{~m}$ and a base diameter of $3-5 \mathrm{~cm}$. This statement is supported by previous studies, which mentions that growing speed may reach $10 \mathrm{~cm} /$ day under optimum ambient conditions. The kenaf plant is composed of many useful components (e.g., stalks, leaves, and seeds) and within each of these there are various usable portions (e.g., fibers and fiber strands, proteins, oils, and allelopathic chemicals). The yield and composition of these plant components can be affected by many factors, including cultivar, planting date, photosensitivity, length of growing season, plant populations, and plant maturity. Kenaf filaments consist of discrete individual fibers, of generally 2 - $6 \mathrm{~mm}$ [11]. Oil palm (Elaeis guineensis Jacq.) is the highest yielding edible oil crop in the world. It is cultivated in 42 countries in 11 million ha worldwide. West Africa, South East Asian countries like Malaysia and Indonesia, Latin American countries and India are the major oil palm cultivating countries [12]. Pineapple leaf fiber (PALF) is obtained from the leaves of the plant, Anannus comosus, belonging to the Bromeliaceae family. PALF is largely cultivated in tropical countries, mainly for its fruits. Its cultivation in India is substantial (about 22, 50,000 acres of land is cultivated and is increasing; in the future a considerable increase in the production of the fiber is envisaged). The pineapple plant has a very short stem which first produces a rosette of leaves but which latter elongated and bears numerous spirally arranged fibrous leaves. The leaves are $3 \mathrm{ft}$. long, 2 to 3 inch wide sword shaped, dark green in color and bear spines of claws on their margins. The leaves of the pineapple plant yield strong, white fine silky fibers. Since the pineapple plant is a special crop, only limited quantity of fiber is available. Therefore, no attempt has been made to grade these fibers [13]. Sisal fiber is a hard fiber extracted from the leaves of the sisal plant (Agave sisalana). Though native to tropical and sub-tropical North and South America, sisal plant is now widely grown in tropical countries of Africa, the West Indies and the Far East. Sisal fibers are extracted from the leaves. A sisal plant produces about $200 \pm 250$ leaves and each leaf contains $1000 \pm 1200$ fiber bundles which are composed of $4 \%$ fiber, $0.75 \%$ cuticle, $8 \%$ dry matter and $87.25 \%$ water. So normally a leaf weighing about $600 \mathrm{~g}$ will yield about $3 \%$ by weight of fiber with each leaf containing about 1000 fibers [14]. Figure 1 shows different kinds of mainly available natural fiber plants.

Industrial uses of natural fibers increasingly gain attention from various manufacturing sectors. The use of natural fibers for polymer composites is growing rapidly to meet diverse end uses in transportation, low cost building, and other construction industries [15]. Qualities of natural fibers are strongly influenced by growing environment, age of plant, species, temperature, humidity, and quality of soil. Various fields where natural fibers can be employed are: structural composites, automobile, non-structural composites, geotextiles, packaging, molded products, sorbents, filters, and in combinations with other materials. Structural beams and panels were designed, manufactured, and tested for bio-based composite materials, particularly on plant oil-based resins and natural fibers [5]. Kenaf and hemp fiber bundles as well as their mixtures significantly increase tensile strength and Young's modulus of composites; they markedly lower the impact strength of pure Poly lactic acid. Thus, these composites should be used for parts that need high tensile strength and stiffness but are subjected to low impact stress. Examples are furniture, boardings or holders for grinding discs. In contrast, cotton fibers cause high impact strength but lower tensile strength and stiffness. These composites could be used for impact stressed components like interior parts in cars or safety helmets. A mixture of bast and cotton could combine the positive tensile characteristics of bast with the good impact properties of cotton, making the composites suitable for various car parts as well as for suitcases [16]. The automobile industry is successfully applying composites reinforced with a variety of natural fiber to replace components such as interior panels and seat cushions originally made of glass mat PMC or polymeric foams [17].

Apart from the plant-based fibers, animal-based fibers become other alternatives for producing biodegradable, biomedical and bio-resorbable composite materials for bioengineering and orthopaedic applications. Silk fiber has been used in biomedical applications particularly as sutures [18]. 


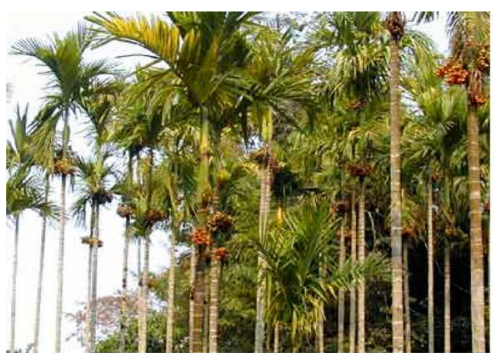

Areca

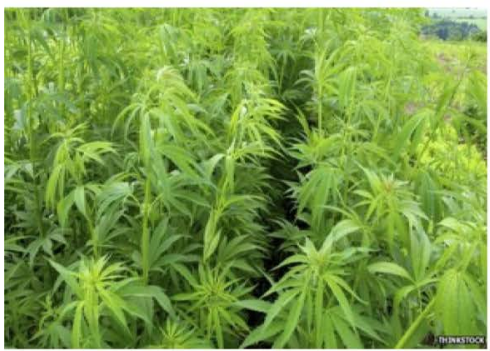

Hemp

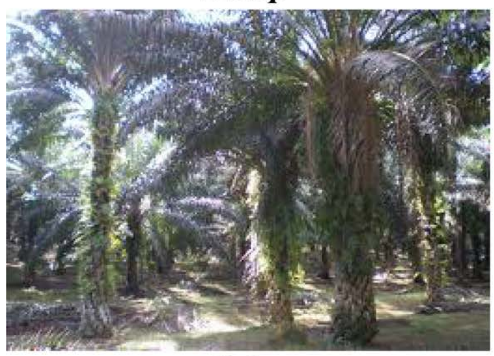

Palm

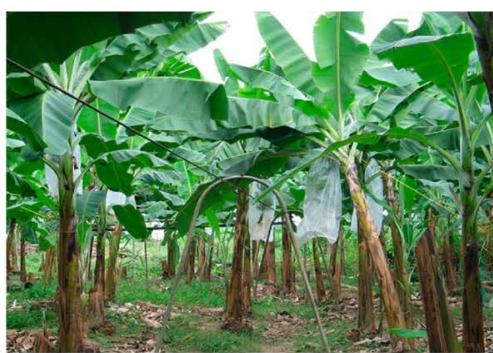

Banana

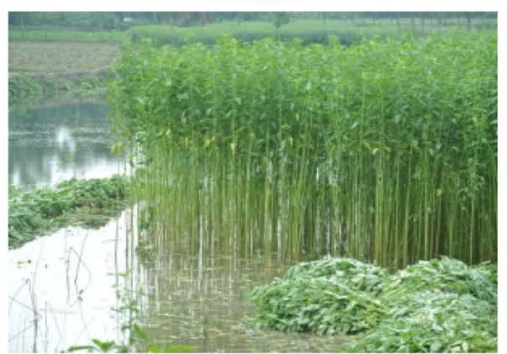

Jute

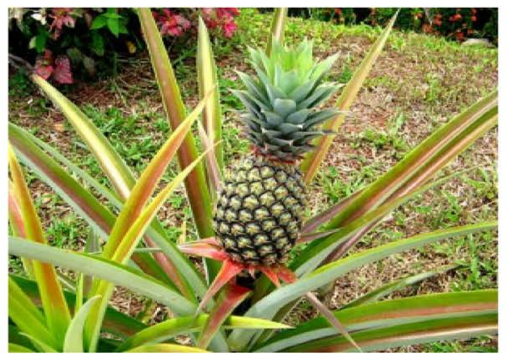

Pineapple

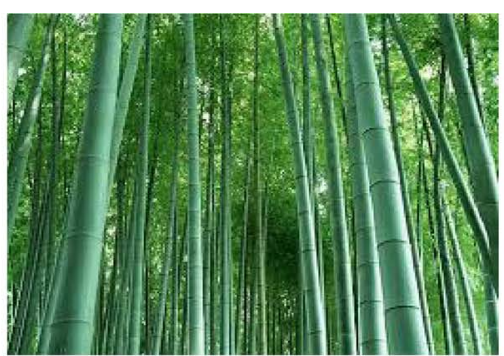

Bamboo

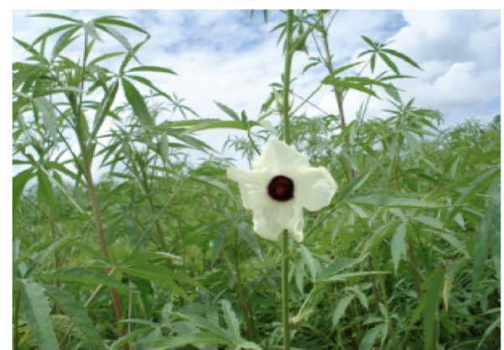

Kenaf

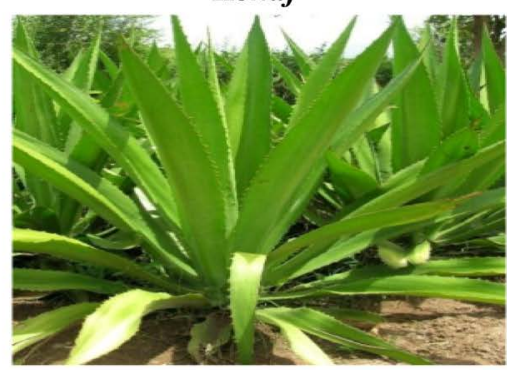

Sisal

Figure 1. Natural fiber plants.

\section{Applications of Natural Fiber Composites}

Natural fibers reinforced composites are emerging very rapidly as the potential substitute to the metal or ceramic based materials in applications that also include automotive, aerospace, marine, sporting goods and electronic industries [19]. Natural fiber composites exhibit good specific properties, but there is high variability in their properties. Their weakness can and will be overcome with the development of more advanced processing of natural fiber and their composites. Their individual properties should be a solid base to generate new applications and opportunities for biocomposites or natural fiber composites in the 21st century "green" materials environment. The exploitation of natural fiber composites in various applications has opened up new avenues for both academicians as well as industries to manufacture a sustainable module for future application of natural fiber composites [20].

In the United States, composite building materials are being made from straw. Straw bales are being used in the construction of buildings. Many automotive components are already produced with natural composites, mainly based on polyester or Polypropylene and fibers like flax, hemp, or sisal. The adoption of natural fiber composites in this industry is led by motives of price, weight reduction, and marketing rather than technical demands [5]. Germany is a leader in the use of natural fiber composites. The German auto-manufacturers, Mercedes, BMW, Audi and Volkswagen have taken the initiative to introduce natural fiber composites for interior and exterior applications. The first commercial example is the inner door panel of the 1999 S-Class MercedesBenz, made in Germany, of 35\% Baypreg F semi-rigid (PUR) elastomer from Bayer and 65\% of a blend of flax, hemp and sisal. It should be emphasized that luxury automotive manufacturers are on board which could be seen as evidence that natural fiber composites are being used for environmental needs and not to lower costs [21]. Mercedes-Benz used an epoxy matrix with the addition of jute in the door panels in its E-class vehicles back in 1996. Another paradigm of natural fiber composites' application appeared commercially in 2000, when Audi 
launched the A2 midrange car: the door trim panels were made of polyurethane reinforced with a mixed flax/sisal material. Toyota developed an eco-plastic made from sugar cane and will use it to line the interiors of the cars [22].

Biodegradable bark cloth reinforced green epoxy composites are developed with view of application to automotive instrument panels [23].The coir/polyester composites have been used to produce mirror casing, paper weights, projector cover, voltage stabilizer cover, mail-box, helmet and roof. In structural applications and infrastructure applications, natural fiber composites have been used to develop load-bearing elements such as beam, roof, multipurpose panel, water tanks and pedestrian bridge [24]. Jute-based green composites would be suitable for even primary structural applications, such as indoor elements in housing, temporary outdoor applications like low-cost housing for defence and rehabilitation and transportation. Due to its insulating characteristics, jute may find areas of applications in automotive door/ceiling panels and panels separating the engine and passenger compartments [25].

\section{Applications of Hybrid Natural Fiber Composites}

The use of natural fiber as reinforcement in polymer matrix focused the attention towards environmental awareness among all over the world. A hybrid composite is a combination of two or more different types of fiber in which one type of fiber balance the deficiency of another fiber [26]. Natural fiber reinforced polymer composites have been proven alternative to Synthetic fiber reinforced polymer composites in many applications [27] [28]. Many Natural fiber composite products being developed and marketed, very few natural fiber composites have been developed, with most of their technologies still in the research and development stages. Natural fiber composites in automobile include for parcel shelves, door panels, instrument panels, armrests, headrests and seat shells [29]. Plastic/wood fiber composites are being used in a large number of applications in decks, docks, window frames and molded panel components [30]. The passenger car bumper beam is manufactured by kenaf/glass epoxy composite material [31]. Recently, banana fiber reinforced composites are coming into in interest due to the innovative application of banana fiber in under-floor protection for passenger cars [32]. Automobile parts such as rear view mirror, visor in two wheeler, billion seat cover, indicator cover, cover L-side, name plate were fabricated using sisal and roselle fibers hybrid composites [33].

\section{Conclusion}

The variety applications of natural fiber and its composites are discussed in this paper. This review concludes that the natural fiber composites form one of the emergent areas in material science that makes awareness for use in various applications.

\section{Acknowledgements}

This research is supported by All India Council for Technical Education (AICTE) (Ref No: 8-191/RFID/RPS/ POLICY-1/2014-15). Authors would like to thank Technical Education Quality Improvement Program of Government of India (TEQIP-II) for financial support.

\section{References}

[1] Ho, M.-P., Wang, H. and Lee, J.-H., Ho, C.-K., Lau, K.-T., Leng, J.S. and Hui, D. (2012) Critical Factors on Manufacturing Processes of Natural Fibre Composites. Composites: Part B, 43, 3549-3562. http://dx.doi.org/10.1016/j.compositesb.2011.10.001

[2] Sathishkumar, T.P., Navaneethakrishnan, P. and Shankar, S. (2012) Tensile and Flexural Properties of Snake Grass Natural Fiber Reinforced Isophthallic Polyester Composites. Composites Science and Technology, 72, 1183-1190. http://dx.doi.org/10.1016/j.compscitech.2012.04.001

[3] Yousif, B.F., Shalwan, A., Chin, C.W. and Ming, K.C. (2012) Flexural Properties of Treated and Untreated Kenaf/Epoxy Composites. Materials and Design, 40, 378-385. http://dx.doi.org/10.1016/j.matdes.2012.04.017

[4] Reddy, N. and Yang, Y.Q. (2005) Biofibers from Agricultural Byproducts for Industrial Applications. Trends in Biotechnology, 23, No.1.

[5] Saravana Bavan., D. and Mohan Kumar, D. (2010) Potential Use of Natural Fiber Composite Materials in India. Journal of Reinforced Plastics and Composites, 29, 3600-3613. http://dx.doi.org/10.1177/0731684410381151 
[6] Mohan Kumar, D. (2008) A Study of Short Areca Fiber Reinforced PF Composites. Proceedings of the World Congress on Engineering, WCE 2008, London, 2-4 July 2008.

[7] Venkateshwaran, N. and Elayaperumal, A. (2010) Banana Fiber Reinforced Polymer Composites-A Review. Journal of Reinforced Plastics and Composites, 29, 2387-2396. http://dx.doi.org/10.1177/0731684409360578

[8] Zakikhani, P., Zahari, R., Sultan, M.T.H. and Majid, D.L. (2014) Extraction and Preparation of Bamboo Fibre-Reinforced Composites. Machine and Design, 63, 820-828.

[9] Shahzad, A. (2012) Hemp Fiber and Its Composites-A Review. Journal of Composite Materials, 46, 973-986. http://dx.doi.org/10.1177/0021998311413623

[10] Gupta, M.K., Srivastava, R.K. and Bisaria, H. (2015) Potential of Jute Fibre Reinforced Polymer Composites: A Review. International Journal of Fiber and Textile Research, 5, 30-38.

[11] Akil, H.M., Omar, M.F., Mazuki, A.A.M., Safiee, S., Ishak, Z.A.M. and Abu Bakar, A. (2011) Kenaf Fiber Reinforced Composites: A Review. Materials and Design, 32, 4107-4121. http://dx.doi.org/10.1016/j.matdes.2011.04.008

[12] Shinoj, S., Visvanathan, R., Panigrahi, S. and Kochubabu, M. (2011) Oil Palm Fiber (OPF) and Its Composites: A Review. Industrial Crops and Products, 33, 7-22. http://dx.doi.org/10.1016/j.indcrop.2010.09.009

[13] Mishra, S., Mohanty, A.K., Drzal, L.T., Misra, M. and Hinrichsen, G. (2004) A Review on Pineapple Leaf Fibers, Sisal Fibers and Their Biocomposites. Macromolecular Materials Engineering, 289, 955-974. http://dx.doi.org/10.1002/mame.200400132

[14] Li, Y., Mai, Y.-W. and Ye, L. (2000) Sisal Fibre and Its Composites: A Review of Recent Developments. Composites Science and Technology, 60, 2037-2055. http://dx.doi.org/10.1016/S0266-3538(00)00101-9

[15] Hao, A., Zhao, H.F. and Chen, J.Y. (2013) Polymer Composites for Automobile Accessories. American Journal of Environmental Science, 9, 494-504. http://dx.doi.org/10.3844/ajessp.2013.494.504

[16] Graupner, N., Herrmann, A.S. and Mussig, J. (2009) Natural and Man-Made Cellulose Fibre-Reinforced Poly(lactic acid) (PLA) Composites: An Overview about Mechanical Characteristics and Application Areas. Composites: Part A, 40, 810-821. http://dx.doi.org/10.1016/j.compositesa.2009.04.003

[17] Monteiro, S.N., Lopes, F.P.D., Ferreira, A.S. and Nascimento, D.C.O. (2009) Natural-Fiber Polymer-Matrix Composites: Cheaper, Tougher, and Environmentally Friendly. JOM, 61, No. 1.

[18] Cheung, H.-Y., Ho, M.-P., Lau, K.-T., Cardona, F. and Hui, D. (2009) Natural Fibre-Reinforced Composites for Bioengineering and Environmental Engineering Applications. Composites: Part B, 40, 655-663. http://dx.doi.org/10.1016/j.compositesb.2009.04.014

[19] Thakur, V.K. and Thakur, M.K. (2014) Processing and Characterization of Natural Cellulose Fibers/Thermoset Polymer Composites. Carbohydrate Polymers, 109, 102-117. http://dx.doi.org/10.1016/j.carbpol.2014.03.039

[20] Gurunathan, T., Mohanty, S. and Nayak, S.K. (2015) A Review of the Recent Developments in Biocomposites Based on Natural Fibres and Their Application Perspectives. Composites: Part A, 77, 1-25. http://dx.doi.org/10.1016/j.compositesa.2015.06.007

[21] Puglia, D., Biagiotti, J. and Kenny, J.M. (2004) A Review on Natural Fibre-Based Composites_Part II: Application of Natural Reinforcements in Composite Materials for Automotive Industry. Journal of Natural Fibres, 1, No. 3.

[22] Koronis, G., Silva, A. and Fontul, M. (2013) Green Composites: A Review of Adequate Materials for Automotive Applications. Composites: Part B, 44, 120-127. http://dx.doi.org/10.1016/j.compositesb.2012.07.004

[23] Rwawiire, S., Tomkova, B., Militky, J., Jabbar, J. and Kale, B.M. (2015) Development of a Biocomposite Based on Green Epoxy Polymer and Natural Cellulose Fabric (Bark Cloth) for Automotive Instrument Panel Applications. Composites: Part B, 81, 149-157. http://dx.doi.org/10.1016/j.compositesb.2015.06.021

[24] Ticoalu, A., Aravinthan, T. and Cardona, F. (2010) A Review of Current Development in Natural Fiber Composites for Structural and Infrastructure Applications. Southern Region Engineering Conference, Toowoomba, 11-12 November 2010, SREC2010-F1-5.

[25] Khondker, O.A., Ishiaku, U.S., Nakai, A. and Hamada, H. (2005) Fabrication and Mechanical Properties of Unidirectional Jute/PP Composites Using Jute Yarns by Film Stacking Method. Journal of Polymers and the Environment, 13, No. 2.

[26] Sanjay, M.R., Arpitha, G.R. and Yogesha, B. (2015) Study on Mechanical Properties of Natural-Glass Fibre Reinforced Polymer Hybrid Composites: A Review. Materials Today: Proceedings, 2, 2959-2967. http://dx.doi.org/10.1016/j.matpr.2015.07.264

[27] Arpitha, G.R., Sanjay, M.R., and Yogesha, B. (2014) Review on Comparative Evaluation of Fiber Reinforced Polymer Matrix Composites. Advanced Engineering and Applied Sciences: An International Journal, 4, 44-47.

[28] Omrani, E., Menezes, E. and Rohatgi, P.K. (2015) State of the Art on Tribological Behavior of Polymer Matrix Com- 
posites Reinforced with Natural Fibers in the Green Materials World. Engineering Science and Technology, an International Journal (in Press). http://dx.doi.org/10.1016/j.jestch.2015.10.007

[29] Satyanarayana, K.G., Arizaga, G.G.C. and Wypych, F. (2009) Biodegradable Composites Based on Lignocellulosic Fibers-An Overview. Progress in Polymer Science, 34, 982-1021. http://dx.doi.org/10.1016/j.progpolymsci.2008.12.002

[30] John, M.J. and Thomas, S. (2008) Biofibers and Biocomposites. Carbohydrate Polymers, 71, 343-364. http://dx.doi.org/10.1016/j.carbpol.2007.05.040

[31] Davoodi, M.M., Sapuan, M.M., Ahmad, D., Ali, A., Khalina, A. and Jonoobi, M. (2010) Mechanical Properties of Hybrid Kenaf/Glass Reinforced Epoxy Composite for Passenger Car Bumper Beam. Materials and Design, 31, 49274932. http://dx.doi.org/10.1016/j.matdes.2010.05.021

[32] Samal, S.K., Mohanty, S. and Nayak, S.K. (2009) Banana/Glass Fiber-Reinforced Polypropylene Hybrid Composites: Fabrication and Performance Evaluation. Polymer-Plastics Technology and Engineering, 48, 397-414. http://dx.doi.org/10.1080/03602550902725407

[33] Chandramohan, D. and Bharanichandar, J. (2013) Natural Fiber Reinforced Polymer Composites for Automobile Accessories. American Journal of Environmental Science, 9, 494-504. http://dx.doi.org/10.3844/ajessp.2013.494.504 